\title{
MiR-34a and miR-206 act as novel prognostic and therapy biomarkers in cervical cancer
}

\author{
Ai-Hua Chen ${ }^{\dagger}$, Yu-E Qin ${ }^{\dagger}$, Wen-Fan Tang ${ }^{\dagger}$, Jing Tao, Hua-mei Song and Manzhen Zuo*
}

\begin{abstract}
Background: Recent evidence indicated that the aberrant expression of microRNA plays a crucial role in the development of cervical cancer. The overall shorter survival was strongly related to the abnormal expression of microRNA34a (miR-34a) and microRNA-206 (miR-206), which target B cell lymphoma-2(Bcl2) and c-Met. Hepatocyte growth factor (HGF)/c-Met pathway is related to the occurrence, development and prognosis of cervical cancer, and c-Met is significantly overexpressed in cervical squamous cell carcinoma. Bcl2 is also considered to be a promising target for developing novel anticancer treatments.
\end{abstract}

Methods: In this study, we detect the expression of miR-34a and miR-206 in the cervical cancer tissue through quantificational real-time polymerase chain reaction (qRT-PCR) assay, and the expression of Bcl2 and c-Met from cervical cancer tissue were detected by immunohistochemistry.

Results: The expression of miR-34a and miR-206 were down-regulated in the cervical cancer tissue through qRT-PCR assay. As target genes of miR-34a and miR-206, Bcl2 and c-Met were up-regulated in cervical cancer tissues through qRT-PCR assay and immunohistochemistry. Kaplan-Meier and log-rank analysis revealed that down-regulated expression of miR-34a and miR-206 were strongly related to shorter overall survival. Multivariate Cox proportional hazards model for all variables that were statistically significant in the univariate analysis demonstrated that miR-34a $(P=0.038)$ and miR-206 $(P=0.008)$ might be independent prognostic factors for overall survival of patients suffering from cervical cancer.

Conclusions: The up-regulation of $\mathrm{Bc} 12$ and c-Met promotes the cervical cancer's progress, and the expression of miR-34a and miR-206 significantly correlated with the progression and prognosis in cervical cancer. All of these suggested that miR-34a and miR-206 might be the novel prognostic and therapy tools in cervical cancer.

Keywords: MiR-34a, MiR-206, qRT-PCR, Cervical cancer

\section{Background}

Cervical cancer is one of the most commonly diagnosed tumors and the main leading cause of tumor death among women especially in developing countries. Lymph node metastasis and local or regional relapse are the primary causes of death in cervical cancer patients. As a protooncogene, c-Met encodes the growth factor receptor for

\footnotetext{
*Correspondence: m15071798480-2@163.com

${ }^{\dagger}$ Ai-Hua Chen, Yu-E Qin and Wen-Fan Tang contributed equally to this work Department of Gynecology and Obstetrics, The People's Hospital of China, China Three Gorges University, The First People's Hospital of Yichang, Yichang, Hubei 443000, China
}

HGF, demonstrates the activity of tyrosine kinase and induces the movement, proliferation and invasion of epithelial cells [1-3]. The activation of HGF/c-Met signal pathway plays an important role in the occurrence and development of human tumors [4-12]. Several studies have shown that c-Met was significantly overexpressed in cervical squamous cell carcinoma and the HGF/c-Met pathway was related to the occurrence, development and prognosis of cervical cancer [13-15]. Moreover, c-Met gene also was thought as a biomarker which was used to evaluate the biological behavior and clinical outcome of cervical cancer [16]. All of these suggest that interference 
with c-Met's activation may provide an effective approach for cervical cancer's treatment, and the expression level of c-Met is an important factor for the diagnosis and prognosis of cervical cancer.

Bcl2 was first discovered as an oncogene in B cell malignancies. Bcl2 is one of the most prominent antiapoptotic proteins and contributes to the tumourigenesis and resistance to current anticancer drugs. Due to the central role in apoptosis regulation, $\mathrm{Bcl} 2$ is a promising target for developing the novel anticancer treatments. Recently, several studies have demonstrated that Bcl2inhibitors may be very beneficial when combined with other targeted agents in solid tumor treatment [17-19].

As noncoding RNA, microRNAs are capable to bind the $3^{\prime}$ - -untranslated region (UTR) of specific genes and act as the inhibitor of corresponding mRNA targets translation. MiRNAs play crucial roles in various biological processes such as differentiation, proliferation and apoptosis [1822]. Several studies have been addressing the impact of miRNAs in tumor development either by acting as oncogenes or tumor suppressor genes [23-25, 27-29]. And previous studies have demonstrated that both $\mathrm{Bcl} 2$ and c-Met are the targets of miR-34a and miR-206 [30-32, 35-40].

In this study, we found that the aberrant expressed microRNAs, miR-34a and miR-206, may play crucial roles through targeting Bcl2 and c-Met genes in cervical cancer tissue. It suggests that miR-34a and miR-206 are potential tools in the prognostic and therapy of cervical cancer.

\section{Methods}

\section{Ethics statement}

All patients agreed to participate in the study and gave written informed consent. This study was approved by the medical ethics committee of China Three Gorges University and complied with the Declaration of Helsinki.

\section{Patients and tissue specimens}

A total of 41 cervical cancer tissues and matched adjacent normal tissues were obtained from patients who underwent surgery in the first hospital of Yichang city, China. The tissue samples were frozen and stored at $-80{ }^{\circ} \mathrm{C}$ after surgical removal until use. The clinical histopathological diagnosis of tissue samples were approved by pathologists. The determination of the clinical stage was performed according to the International League of Gynecology and Obstetrics (FIGO).

\section{Extraction of RNA and qRT-PCR}

In brief, the total RNA was extracted from collected samples with using TRIzol reagent (Invitrogen, Carlsbad, CA, USA). MiraMasTM Kit (Bioo Scientific, USA) was applied to perform the reverse-transcription reactions. RT-PCR analyses for genes were done with using
SYBR green (Takara, Japan) on applied biosystems 7500 real-time PCR system, U6 gene was applied as references (Additional file 1). Moreover, the relative expressions of miRNAs were analyzed with the comparative cycle threshold (CT) method-fold change $\left(2^{-\Delta \Delta C T}\right)$.

\section{Immunohistochemistry}

All of the cervical tissue specimens were fixed with $10 \%$ neutral formalin embedded with paraffin, and serially sectioned at $5 \mu \mathrm{m}$. The sections were mounted onto the histostick-coated slides. Four or five adjacent ribbons were collected for histopathological analysis and for immunohistochemical staining. Histopathological diagnosis for tumor tissues was made according to cellular morphological changes and tissue architecture using the previously established criteria.

The biotin-streptavidin complex method was used for the immunostaining of c-Met, Bcl2. In brief, after dewaxing, inactivating the endogenous peroxidase activity and blocking cross-reactivity with normal non-immune goat serum, the sections were incubated at $4{ }^{\circ} \mathrm{C}$ overnight with a diluted solution of the first antibodies. The location of the primary antibodies was achieved by the subsequent application of a biotin-conjugated IgG ( $2^{\mathrm{d}}$ antibody), a streptavidin-peroxidase. The color was visualized with $\mathrm{DAB}$ and the cellular nuclei were counterstained with instant hematoxylin. Negative controls were stablished by replacing the primary antibody with normal isotype serum.

\section{Follow-up}

The patients were followed every 6 months for 2 years and then annually, thereafter. The total follow-up period was defined as the time from diagnosis to the date of death or the last censused date if the patients are still alive. There are all 41 patients that are included in the survival data analysis.

\section{Statistical analysis}

All variables were analyzed by software SPSS version 17.0 (SPSS Inc, Illinois, USA). The Chi square test was used to investigate the association of miRNA expression with clinical parameters. The log-rank test and KaplanMeier method were applied for the evaluation of survival rate. Multivariate Cox regression was used to analyze the independent prognostic factors that were related to the survival of patients. Statistical significance was concluded at $P<0.05$.

\section{Results}

c-Met and Bcl2 up-regulated promote cervical cancer progress.

Consistent with previous researches [14, 15, 18, 19], c-Met and $\mathrm{Bcl} 2$ were up-regulated in cervical cancer tissues through immunohistochemistry in our study (Fig. 1). 


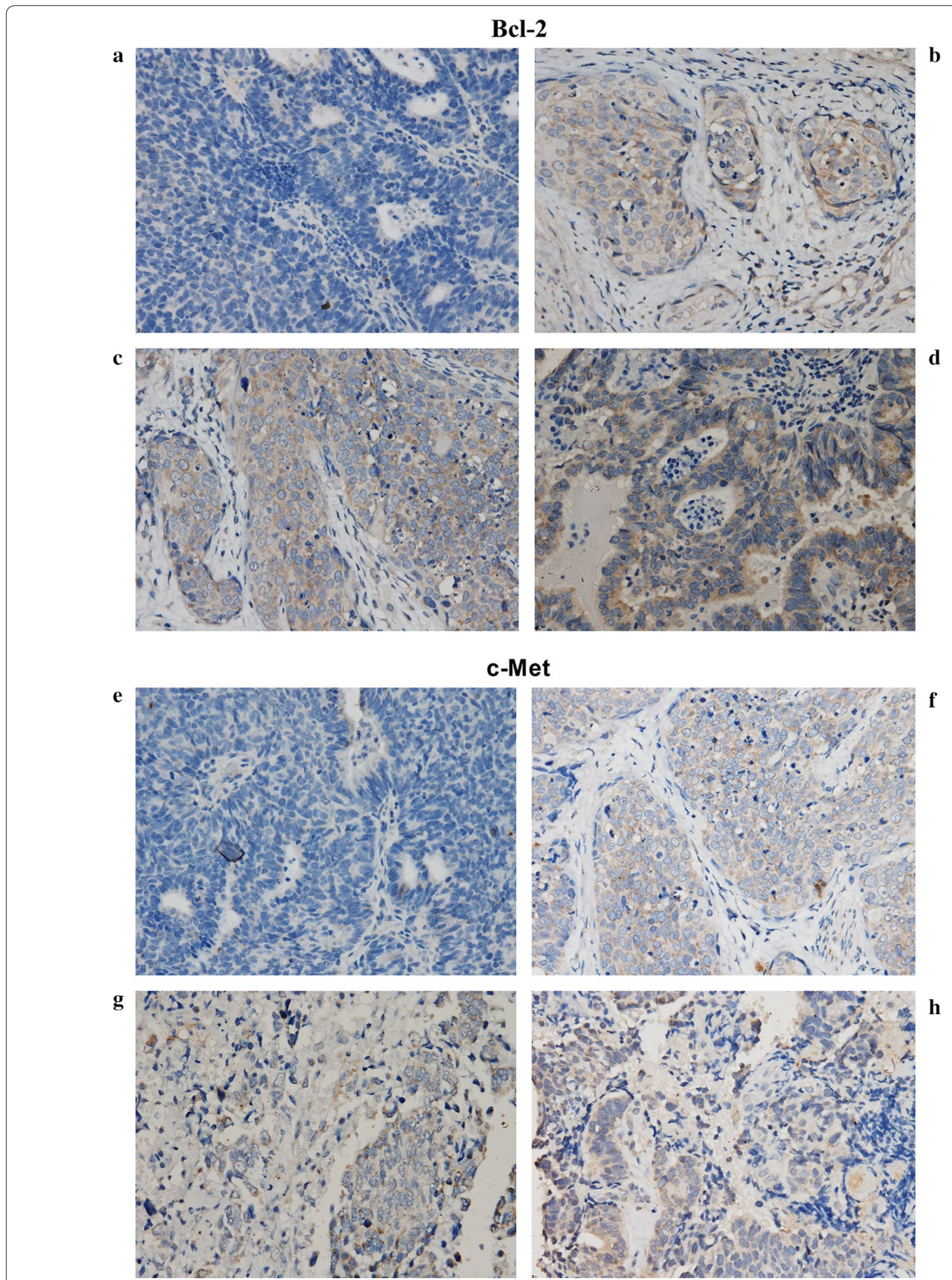

Fig. 1 Comparison of $\mathrm{Bc} / 2$ and c-Met expression level between cervical cancer tissues and normal tissues. a and e: tumor-adjacent normal cervical tissue; $\mathbf{b}$ and $\mathbf{f}: \mid \mathrm{b} ; \mathbf{c}$ and $\mathbf{g}$ : IIIa; $\mathbf{d}$ and $\mathbf{h}$ : IIIb. a, b, c, d: Bcl2; e, f, g, h: c-Met 
Patients with elevated expression of Bcl2 and c-Met tend to have lymph node metastasis $(P=0.000, P=0.001)$, advanced stage $(P=0.00)$ (Table 1$)$. These results indicated that $\mathrm{Bcl} 2$ and c-Met involved in the metastasis and progression in patients with cervical cancer. Inconsistent with other studies, elevated expression of $\mathrm{Bcl} 2$ and c-Met showed no significant correlation with advanced histological grade $(P=0.056, P=0.06)$ in our study (Table 1$)$. This may be due to the cases in our study are more moderate differentiated so that the correlation between the up-regulated $\mathrm{Bcl} 2$ and c-Met and the advanced histological grade is not obvious.

Kaplan-Meier and log-rank analysis revealed that the up-regulated expression of Bcl2 and c-Met were strongly related to shorter survival (Figs. 2, 3). Multivariate Cox proportional hazards model for all variables that were statistically significant in the univariate analysis demonstrated that high expression of $\mathrm{Bcl} 2$ and c-Met might be independent prognostic factors for the overall survival of the patients suffering from cervical cancer (Tables 2, 3).

miR-34a and miR-206 expression significantly correlated with progression and prognosis in cervical cancer.

According to bioinformatics and the previous experiment results, both $\mathrm{Bcl} 2$ and c-Met are the targets of miR-34a and miR-206. Through Q-PCR, we found miR-34a and miR-206 were down regulated in cervical cancer tissue compare with tumor-adjacent normal cervical tissue (Fig. 4). Patients with decreased expression of miR-34a and miR-206 tend to have lymph node metastasis $(P=0.000, P=0.001)$, advanced stage $(P=0.000, P=0.000)$, advanced histological grade $(P=0.029, P=0.023)$ (Table 4$)$. These results indicate that miR-34a and miR-206 might be involved in the metastasis and progression in patients with cervical cancer.

Kaplan-Meier and log-rank analysis revealed that the down-regulated expression of miR-34a and miR206 were strongly related to a shorter overall survival (Figs. 5, 6). Multivariate Cox proportional hazards model for all variables that were statistically significant in the univariate analysis demonstrated that miR-34a $(P=0.038)$ and miR-206 $(P=0.008)$ might be independent prognostic factors for the overall survival of the patients suffering from cervical cancer (Tables 5, 6).

\section{Discussion}

Since bioinformatic studies have indicated that $30-50 \%$ of human genes' expressions are probably controlled by miRNAs, it is conceivable that more miRNAs will play a critical role in cervical cancer's occurrence and can potentially serve as biomarkers and targets for anticancer therapy $[24,25]$. MiR-34a has been reported to be a key regulator of tumor suppression and down-regulated in several cancers, it involved in the occurrence and development of cancer [26]. MiR-34a is implicated in p53 network as the direct activator of p53. Wild type p53 induces the transcription of miR-34a which targets several molecules that are involved in cellular transformation and carcinogenesis [27-29]. The abnormal miR-34a expression has been revealed in breast cancer [31], colon cancer [32], cervical cancer [33], prostate cancer [34], esophageal squamous cell carcinoma [37], and lung cancer [38]. MiR-34a may act on its target genes to regulate

Table 1 Association of Bcl2 and c-Met expression with clinicopathological features

\begin{tabular}{|c|c|c|c|c|c|c|c|}
\hline \multirow[t]{2}{*}{ Variables } & \multirow[t]{2}{*}{ No. of cases } & \multicolumn{2}{|c|}{ No. of expression of Bc12 } & \multicolumn{2}{|c|}{ No. of expression of c-Met } & \multirow[t]{2}{*}{$\mathrm{Bc} 12(P)$} & \multirow[t]{2}{*}{ C-Met $(P)$} \\
\hline & & Low $=30$ & High $=11$ & Low $=29$ & High $=12$ & & \\
\hline \multicolumn{8}{|l|}{ Tumor size (cm) } \\
\hline$>4$ & 18 & 17 & 1 & 17 & 1 & 0.011 & 0.005 \\
\hline$\leq 4$ & 23 & 13 & 10 & 12 & 11 & & \\
\hline \multicolumn{8}{|l|}{ Histological grades } \\
\hline Well differentiated & 4 & 4 & 0 & 4 & 0 & 0.056 & 0.06 \\
\hline Moderate differentiated & 34 & 25 & 9 & 24 & 10 & & \\
\hline Poorly differentiated & 3 & 1 & 2 & 1 & 2 & & \\
\hline \multicolumn{8}{|l|}{ FIGO stage } \\
\hline Ib-Ila & 25 & 24 & 1 & 25 & 0 & 0.000 & 0.000 \\
\hline IIb-IIla & 12 & 6 & 6 & 4 & 8 & & \\
\hline Illb above & 4 & 0 & 4 & 0 & 4 & & \\
\hline \multicolumn{8}{|l|}{ Lymph node metasis } \\
\hline Yes & 17 & 7 & 10 & 7 & 10 & 0.000 & 0.001 \\
\hline No & 24 & 23 & 1 & 22 & 2 & & \\
\hline
\end{tabular}



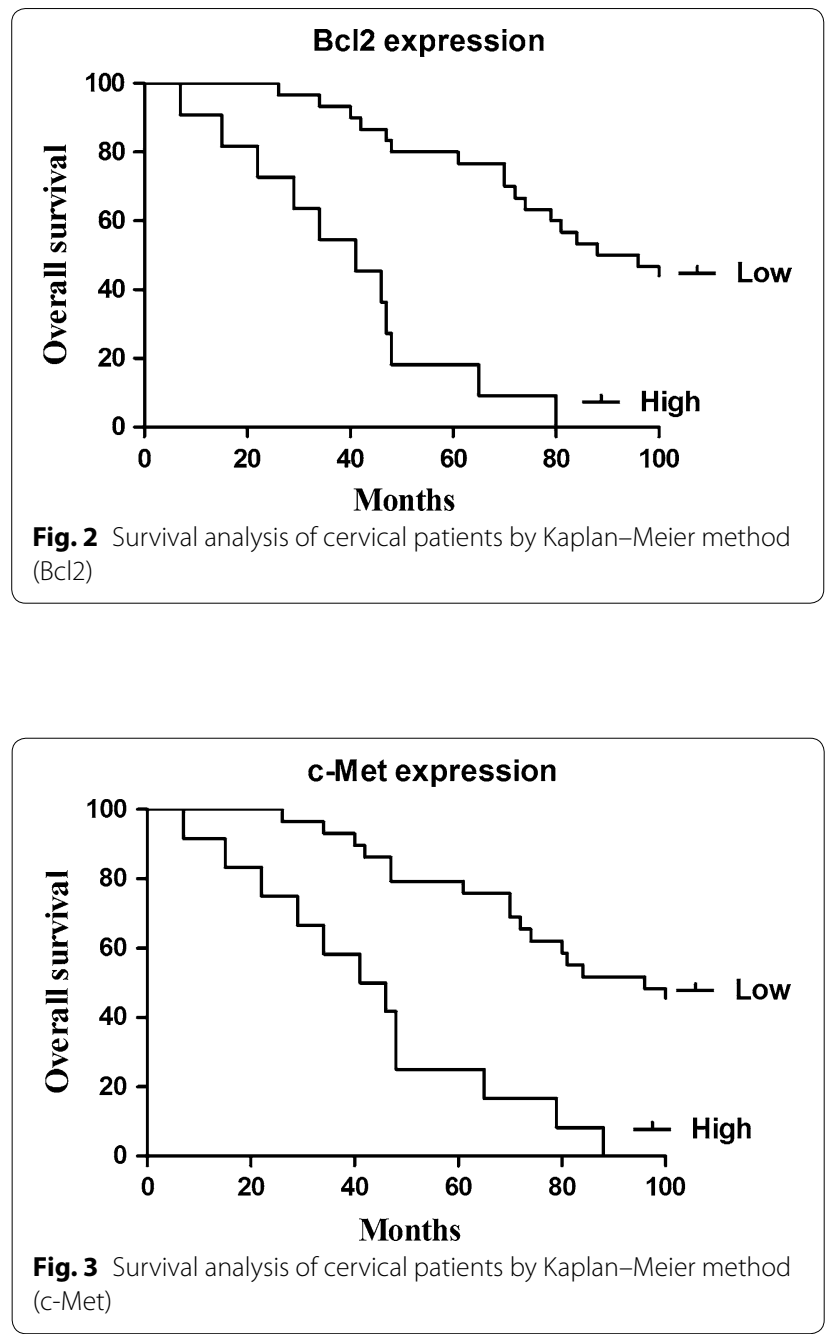

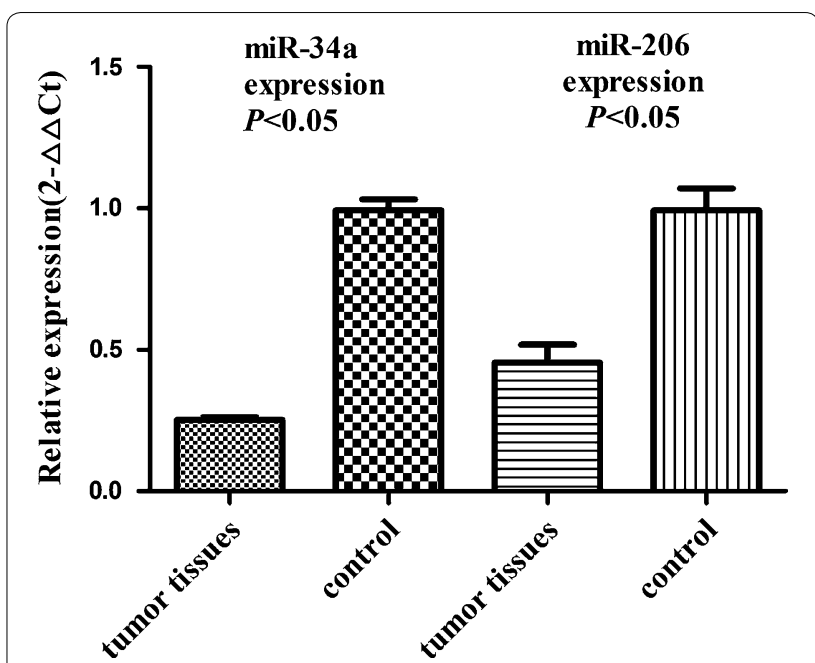

Fig. 4 Comparison of miR-34a and miR-206 expression level between cervical cancer tissues and normal tissues

the proliferation, apoptosis, invasion, metastasis and epithelial mesenchymal transition of cancer cells, exert inhibitory effects on the growth and metastasis of cancers [39]. In our research, we found miR-34a down-regulated in cervical cancer tissue and it might be involved in the metastasis and progression in patients with cervical cancer through targeting $\mathrm{Bcl} 2$ and c-Met which have been confirmed as targets of miR-34a [40, 41]. Besides $\mathrm{Bcl} 2$ and c-Met, other miR-34a target genes have been reported in different biological context, such as SIRT1, SIRT6, PNUTS, TGIF2 and HDAC1 which are closely related to cell proliferation, differentiation, apoptosis and

Table 2 Univariate and multivariate analysis of prognostic parameters by $\operatorname{Cox}(\mathrm{Bcl} 2)$

\begin{tabular}{llll}
\hline Clinicopathological characteristics & Relative risk (RR) & Univariate log-rank test $(\boldsymbol{P})$ & Cox multivariable analysis $(\boldsymbol{P})$ \\
\hline Tumor diameter $(\mathrm{cm})$ & 1.220 & 0.03 & 0.791 \\
Histological grades & 0.422 & 0.04 & 0.188 \\
$\mathrm{FIGO}$ stage & 1.486 & 0.002 & 0.04 \\
Lymph node metastasis & 6.130 & 0.001 & 0.001 \\
$\mathrm{BCl}_{2}$ expression (high/low) & 1.554 & 0.002 & 0.008 \\
\hline
\end{tabular}

Table 3 Univariate and multivariate analysis of prognostic parameters by Cox (c-Met)

\begin{tabular}{llll}
\hline Clinicopathological characteristics & Relative risk (RR) & Univariate log-rank test $(\boldsymbol{P})$ & Cox multivariable analysis $(\boldsymbol{P})$ \\
\hline Tumor diameter (cm) & 1.148 & 0.042 & 0.801 \\
Histological grades & 0.409 & 0.056 & 0.202 \\
FIGO stage & 1.496 & 0.003 & 0.04 \\
Lymph node metastasis & 6.695 & 0.001 & 0.000 \\
C-Met expression (high/low) & 1.651 & 0.007 & 0.039 \\
\hline
\end{tabular}


Table 4 Association of miR-34a and miR-206 expression with clinicopathological features

\begin{tabular}{|c|c|c|c|c|c|c|c|}
\hline \multirow[t]{2}{*}{ Variables } & \multirow[t]{2}{*}{ No. of cases } & \multicolumn{2}{|c|}{ No. of expression of miR-34a } & \multicolumn{2}{|c|}{ No. of expression of miR-206 } & \multirow[t]{2}{*}{ miR-34a $(P)$} & \multirow[t]{2}{*}{$\operatorname{miR}-206(P)$} \\
\hline & & Low $=21$ & $\mathrm{High}=20$ & Low $=23$ & High $=18$ & & \\
\hline \multicolumn{8}{|l|}{ Tumor size (cm) } \\
\hline$>4$ & 18 & 4 & 14 & 5 & 13 & 0.002 & 0.002 \\
\hline$\leq 4$ & 23 & 17 & 6 & 18 & 5 & & \\
\hline \multicolumn{8}{|l|}{ Histological grades } \\
\hline Well differentiated & 4 & 0 & 4 & 0 & 4 & 0.029 & 0.023 \\
\hline Moderate differentiated & 34 & 18 & 16 & 20 & 14 & & \\
\hline Poorly differentiated & 3 & 3 & 0 & 3 & 0 & & \\
\hline \multicolumn{8}{|l|}{ FIGO stage } \\
\hline |b- $\mid l a$ & 25 & 24 & 1 & 7 & 18 & 0.000 & 0.000 \\
\hline IIb-IIla & 12 & 6 & 6 & 12 & 0 & & \\
\hline Illb above & 4 & 0 & 4 & 4 & 0 & & \\
\hline \multicolumn{8}{|l|}{ Lymph node metasis } \\
\hline Yes & 17 & 15 & 2 & 17 & 0 & 0.000 & 0.001 \\
\hline No & 24 & 6 & 18 & 6 & 18 & & \\
\hline
\end{tabular}

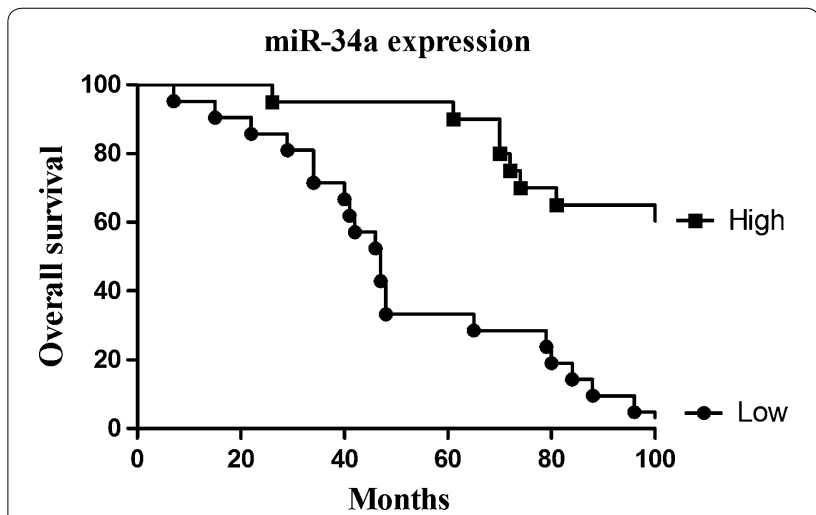

Fig. 5 Survival analysis of cervical patients by Kaplan-Meier method (miR-34a)

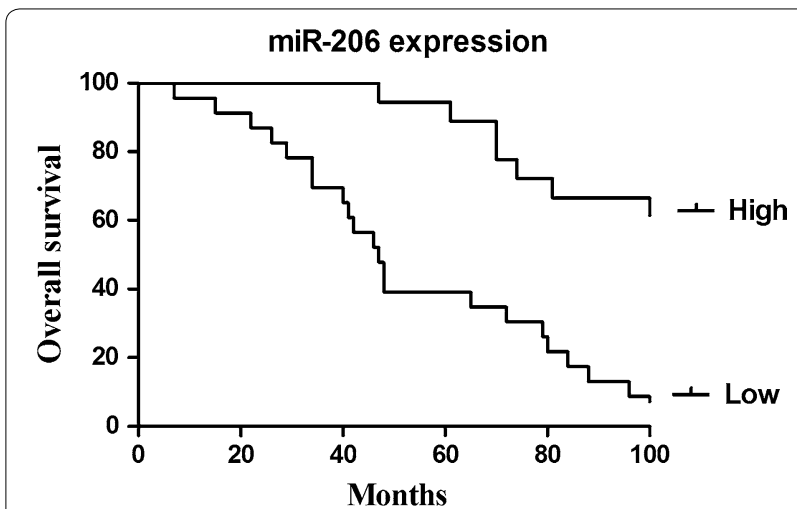

Fig. 6 Survival analysis of cervical patients by Kaplan-Meier method (miR-206) other biological processes [42, 43]. As same as Bcl2 and c-Met, these genes also play crucial roles in the development of cancer. MiR-34a also has been found down-regulated in high-risk HPV infected tissues, which resulted from HPV-E6 expression [30]. HPV-E6 down-regulate the expression of miR-34a by degrading p53 through ubiquitin-proteasome system. High-risk HPVs are recognized to be the main cause for the development of cervical cancer. So the miR-34a down-regulation in cervical cancer tissue might be closely related with the high-risk HPVs infection. All of these suggested that miR-34a is a key tumor suppressor and a potential prognostic and therapy biomarker in cervical cancer.

As a skeletal muscle-enriched miRNA, miR-206 inhibits the proliferation of progenitor cells and promotes the myogenesis [44]. However, further studies showed that miR-206 is down-regulated in breast cancer, melanoma tumors and other various types of human cancers [45]. These researchers proposed that the down expression of miR-206 may be linked with cancer's development. Several studies indicated that miR-206 induces G1 arrest in melanoma cell lines and function as a pro-apoptotic factor in HeLa cells through targeting Notch3 signal pathway [45-47]. MiR-206 also promoted the myogenic differentiation and blocked the tumor growth in xenografted mice by the down-regulation of Met tyrosine-kinase receptor, the product of the MET proto-oncogene [48]. Researchers further showed that the decrease in miR-206 expression is associated with an increase in oncogene CCND1, CCND2 and MMP-9, and also a decrease in p57. CCND1 and CCND2 are well-established oncogenes in many 
Table 5 Univariate and multivariate analysis of prognostic parameters by Cox (miR-34a)

\begin{tabular}{llll}
\hline Clinicopathological characteristics & Relative risk (RR) & Univariate log-rank test $(\boldsymbol{P})$ & Cox multivariable analysis $(\boldsymbol{P})$ \\
\hline Tumor diameter $(\mathrm{cm})$ & 1.001 & 0.047 & 0.998 \\
Histological grades & 0.450 & 0.032 & 0.218 \\
FIGO stage & 1.757 & 0.002 & 0.038 \\
Lymph node metastasis & 6.567 & 0.001 & 0.001 \\
miR-34a expression (high/low) & 1.409 & 0.002 & 0.038 \\
\hline
\end{tabular}

Table 6 Univariate and multivariate analysis of prognostic parameters by Cox (miR-206)

\begin{tabular}{llll}
\hline Clinicopathological characteristics & Relative risk (RR) & Univariate log-rank test $(\boldsymbol{P})$ & Cox multivariable analysis $(\boldsymbol{P})$ \\
\hline Tumor diameter (cm) & 1.170 & 0.036 & 0.775 \\
Histological grades & 0.478 & 0.041 & 0.238 \\
FIGO stage & 1.984 & 0.002 & 0.01 \\
Lymph node metastasis & 7.753 & 0.001 & 0.002 \\
miR-206 expression (high/low) & 1.885 & 0.002 & 0.008 \\
\hline
\end{tabular}

different cancers [49, 50]. MicroR-206 also acts as a tumor suppressor in bladder cancer and colorectal cancer via targeting YRDC and FMNL2, which are closely related to the tumor cell proliferation and EMT [51, 52]. Sun et al. found that the down-regulation of c-Met and $\mathrm{Bcl} 2$ by microRNA-206, can activates apoptosis, inhibits tumor cell proliferation, migration and colony formation in human lung cancer [47]. In our study, we also found that miR-206 down-regulated in cervical cancer tissues from patients, and the expression of c-Met and $\mathrm{Bcl} 2$ were up-regulated. And patients with decreased expression of miR-206 tended to have lymph node metastasis $(P=0.001)$, advanced stage $(P=0.000)$, advanced histological grade $(P=0.023)$.

Moreover, Kaplan-Meier and log-rank analysis revealed that the down-regulated expression of miR-34a and miR-206 were strongly related to shorter overall survival. Multivariate Cox proportional hazards model for all variables that were statistically significant in the univariate analysis demonstrated that miR-34a $(P=0.038)$ and miR-206 ( $P=0.008)$ might be independent prognostic factors for the overall survival of patients suffering from cervical cancer. All of these results in our study suggested that miR-34a and miR-206 might be involved in the progression and prognosis of cervical cancer through targeting $\mathrm{Bcl} 2$ and $\mathrm{c}-\mathrm{Met}$. Besides $\mathrm{Bcl} 2$ and $\mathrm{c}-\mathrm{Met}$, which were significantly up-regulated in cervical cancer in our study, other target genes of miR-34 and miR-206 may also play crucial roles in the progression of cervical cancer tissue and which is the dominant role remain to be definite. Anyway, the down-regulation of miR-34a and miR-206 expression levels has the potential in acting as biomarker of the aggressive progression and the poor prognosis in cervical cancer.

\section{Conclusion}

Based on previous studies which have demonstrated that $\mathrm{Bcl} 2$, c-Met are closely related with cervical cancer progression, we found their regulators, miR-34a and miR206, also play important roles in the development and prognosis of cervical cancer. Patients with decreased expression of miR-34a and miR-206 tended to have lymph node metastasis, advanced stage, advanced histological grade and shorter survival in our study. It suggested that miR-34a and miR-206 also have the potential in acting as biomarkers of aggressive progression and poor prognosis in cervical cancer.

\section{Additional file}

Additional file 1. Sequence of the primers used in this study

\section{Abbreviations}

miRNA: microRNA; miR-34a: microRNA-34a; miR-206: microRNA-206a; Bcl2: B-cell lymphoma-2; HGF: hepatocyte growth factor; qRT-PCR: quantificational real-time polymerase chain reaction.

\section{Authors' contributions}

A-HC carried out immunohistochemistry, participated in the design of the study and statistical analysis, Y-EQ carried out qRT-PCR assay and participated in the draft of the manuscript, W-FT, participated in immunohistochemistry and qRT-PCR assay, participated in the draft of the manuscript, JT and H-MS collected pathologic specimens, participated in the design of the study, $\mathrm{MZ}$ as corresponding author conceived the study, and participated in its design, coordination and helped to draft the manuscript. All authors read and approved the final manuscript. 


\section{Competing interests}

The authors declare that they have no competing interests.

\section{Availability interests}

The datasets analysed during the current available from the corresponding authors on reasonable request.

\section{Consent of publication}

All authors are responsible for the submission of this article and accept the conditions of submission.

\section{Ethical approval}

Ethical approval was given by the Medical Ethics Committee of The First People's Hospital of Yichang.

\section{Funding}

The Health Science and Technology Project of Yichang (A14301-21).

\section{Publisher's Note}

Springer Nature remains neutral with regard to jurisdictional claims in published maps and institutional affiliations.

Received: 21 January 2017 Accepted: 29 May 2017

Published online: 09 June 2017

\section{References}

1. Matsumoto K, Nakamura T. Hepatocyte growth factor (HGF) as a tissue organizer for organogenesis and regeneration. Biochem Biophys Res Commun. 1997;239(3):639-44.

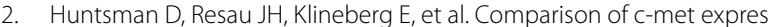
sion in ovarian epithelial tumors and normal epithelia of the female reproductive tract by quantitative laser scan microscopy. Am J Pathol. 1999;155(2):343-8.

3. Furge KA, Zhang Y-W, Vande Woude GF. Met receptor tyrosine kinase: enhanced signaling through adapter proteins. Oncogene. 2000;19(49):5582-9.

4. Agwa ES, Ma PC. Targeting the MET receptor tyrosine kinase in nonsmall cell lung cancer: emerging role of tivantinib. Cancer Manag Res. 2014:6:397-404

5. Yamaguchi $\mathrm{R}$, Yano $\mathrm{H}$, lemura $\mathrm{A}$, et al. Expression of vascular endothelial growth factor in human hepatocellular carcinoma. Hepatology. 1998;28(1):68-77

6. Koo BS, Kim JM, Seo ST, et al. Upregulation of HGF and c-MET is associated with subclinical central lymph node metastasis in papillary thyroid microcarcinoma. Ann Surg Oncol. 2014;21(7):2310-7.

7. Fuse N, Kuboki Y, Kuwata T, et al. Prognostic impact of HER2, EGFR, and c-MET status on overall survival of advanced gastric cancer patients. Gastric Cancer. 2016;19(1):183-91.

8. Neuzillet C, Couvelard A, Tijeras-Raballand A, et al. High c-Met expression in stage I-II pancreatic adenocarcinoma: proposal for an immunostaining scoring method and correlation with poor prognosis. Histopathology. 2015:67(5):664-76.

9. Yan $\mathrm{S}$, Jiao $\mathrm{X}, \mathrm{Zou} \mathrm{H}$, et al. Prognostic signifiance of cMet in breast cancer: a meta-analysis of 6010 cases. Diagn Pathol. 2015;10:62.

10. Han Y, Luo Y, Zhao J, et al. Overexpression of c-Met increases the tumor invasion of human prostate LNCaP cancer cells in vitro and in vivo. Oncol Lett. 2014;8(4):1618-24.

11. Leo C, Horn L-C, Einenkel J, et al. Tumor hypoxia and expression of c-met in cervical cancer. Gynecol Oncol. 2007;104(1):181-5.

12. Yoshida S, Harada T, Iwabe T, et al. Induction of hepatocyte growth factor in stromal cells by tumor-derived basic fibroblast growth factor enhances growth and invasion of endometrial cancer. J Clin Endocrinol Metab. 2002:87(5):2376-83.

13. Kanayama S, Yamada Y, Kawaguchi R, et al. Hepatocyte growth factor induces anoikis resistance by up-regulation of cyclooxygenase-2 expression in uterine endometrial cancer cells. Oncol Rep. 2008;19(1):117-22.
14. Han SY, Jia S, Jia CR, et al. The correlation between expression of the hepatocyte growth factor and c-Met/hepatocyte growth factor receptor and the invasion and metastasis of uterine cervix cancer. Chin J Clin Oncol. 2006;12(1):1214-6.

15. Refaat T, Donnelly ED, Sachdev S, et al. c-Met overexpression in cervical cancer, a prognostic factor and a potential molecular therapeutic target. Am J Clin Oncol. 2015.

16. Peng J, Qi S, Wang P, et al. Diagnosis and prognostic significance of c-Met in cervical cancer: a meta-analysis. Dis Mark. 2016;2016:6594016.

17. Vogler M. Targeting BCL2-proteins for the treatment of solid tumours. Adv Med. 2014;2014:943648

18. Pillai MR, Halabi S, McKalip A, et al. The presence of human papillomavirus-16/-18 E6, p53, and Bcl-2 protein in cervicovaginal smears from patients with invasive cervical cancer. Cancer Epidemiol Biomark Prev. 1996;5(5):329-35.

19. Dimitrakakis C, Kymionis G, Diakomanolis E, et al. The possible role of p53 and bcl-2 expression in cervical carcinomas and their premalignant lesions. Gynecol Oncol. 2000;77(1):129-36.

20. Liu L, Yu X, Guo X, et al. miR-143 is downregulated in cervical cancer and promotes apoptosis and inhibits tumor formation by targeting $\mathrm{BCl}-2 . \mathrm{Mol}$ Med Rep. 2012;5(3):753-60

21. Cadamuro AC, Rossi AF, Maniezzo NM, et al. Helicobacter pylori infection: host immune response, implications on gene expression and microRNAs. World J Gastroenterol. 2014;20(6):1424-37.

22. Curtale G, Mirolo M, Renzi TA, et al. Negative regulation of Toll-like receptor 4 signaling by IL-10-dependent microRNA-146b. Proc Natl Acad Sci U SA. 2013:110(28):11499-504.

23. Hermeking $\mathrm{H}$. MicroRNAs in the $\mathrm{p} 53$ network: micromanagement of tumour suppression. Nat Rev Cancer. 2012;12(9):613-26.

24. He L, He X, Lim LP, et al. A microRNA component of the p53 tumour suppressor network. Nature. 2007;447(148):1130-4.

25. He X, He L, Hannon GJ. The guardian's little helper: microRNAs in the p53 tumor suppressor network. Cancer Res. 2007:67(23):11099-101.

26. Bhavna K, Arti Y, James L, et al. Dysrefulation of MicroRNA-34a expression in head and neck squamous cell carcinoma promotes tumor growth and tumor angiogenesis. PLoS ONE. 2012;7(5):e37601.

27. Bommer GT, Gerin I, Feng Y, et al. p53-mediated activation of miRNA34 candidate tumor-suppressor genes. Curr Biol. 2007;17(15):1298-307.

28. Chang TC, Wentzel EA, Kent OA, et al. Transactivation of miR-34a by p53 broadly inflences gene expression and promotes apoptosis. Mol Cell. 2007;26(5):745-52.

29. Corney DC, Flesken-Nikitin A, Godwin AK, et al. MicroRNA-34b and microRNA-34c are targets of p53 and cooperate in control of cell proliferation and adhesion independent growth. Cancer Res. 2007:67(18):8433-8.

30. Li B, Hu Y, Ye F, et al. Reduced miR-34a expression in normal cervical tissues and cervical lesions with high-risk human papillomavirus infection. Int J Gynecol Cancer. 2010;20(4):597-604.

31. Li L, Yuan L, Luo J, et al. MiR-34a inhibits proliferation and migration of breast cancer through down-regulation of $\mathrm{BCl}-2$ and SIRT1. Clin Exp Med. 2013;13:109-17.

32. Mohan M, Kumar V, Lackner AA, et al. Dysregulated miR-34a-SIRT1-acetyl p65 axis is a potential mediator of immune activation in the colon during chronic simian immunodeficiency virus infection of rhesus macaques. J Immunol. 2015;194:291-306.

33. Geng D, Song X, Ning F, et al. MiR-34a inhibits viability and invasion of human papillomavirus-positive cervical cancer cells by targeting E2F3 and regulating survivin. Int J Gynecol Cancer. 2015:25:707-13.

34. Kashat M, Azzouz L, Sarkar SH, et al. Inactivation of AR and Notch-1 signaling by miR-34a attenuates prostate cancer aggressiveness. Am J Trans Res. 2012:4:432-42.

35. Ma G, Wang Y, Li Y, et al. MiR-206, a key modulator of skeletal muscle development and disease. Int J Biol Sci. 2015;11(3):345-52.

36. Alteri A, De Vito F, Messina G, et al. Cyclin D1 is a major target of miR-206 in cell differentiation and transformation. Cell Cycle. 2013;12(24):3781-90.

37. Nie J, Ge X, Geng Y, Cao H, Zhu W, Jiao Y, Wu J, Zhou J, Cao J. miR-34a inhibits the migration and invasion of esophageal squamous cell carcinoma by targeting Yin Yang-1. Oncol Rep. 2015;34:311-7.

38. Garofalo M, Jeon YJ, Nuovo GJ, et al. Correction: miR-34a/c-dependent PDGFR-alpha/beta downregulation Inhibits tumorigenesis and enhances TRAIL-induced apoptosis in lung cancer. PLoS ONE. 2015;10:e0131729. 
39. Li L. Regulatory mechanisms and clinical perspectives of miR-34a in cancer. J Cancer Res Ther. 2014;10:805-10.

40. Dang Y, Luo D, Rong M, et al. Underexpression of miR-34a in hepatocellular carcinoma and its contribution towards enhancement of proliferating inhibitory effects of agents targeting c-MET. PLoS ONE. 2013;8(4):e61054.

41. Chen H, Wang J, Hu B, et al. MiR-34a promotes Fas-mediated cartilage endplate chondrocyte apoptosis by targeting $\mathrm{BCl}-2$. Mol Cell Biochem. 2015;406(1-2):21-30.

42. Wu S, He X, Li M, et al. MiRNA-34a overexpression inhibits multiple myeloma cancer stem cell growth in mice by suppressing TGIF2. Am J Transl Res. 2016;8(12):5433-43.

43. Sun TY, Xie HJ, Li Z, et al. MiR-34a regulates HDAC1 expression to affect the proliferation and apoptosis of hepatocellular carcinoma. Am J Transl Res. 2017;9(1):103-14.

44. Nohata N, Hanazawa T, Enokida H, et al. microRNA-1/133a and microRNA206/133b clusters: dysregulation and functional roles in human cancers. Oncotarget. 2012;3(1):9-21.

45. Kondo N, Toyama T, Sugiura H, et al. miR-206 expression is down-regulated in estrogen receptor alpha-positive human breast cancer. Cancer Res. 2008;68(13):5004-8.

46. Song G, Zhang Y, Wang L. MicroRNA-206 targets notch3, activates apoptosis, and inhibits tumor cell migration and focus formation. J Biol Chem. 2009;284(46):31921-7.
47. Sun C, Liu Z, Li S, et al. Down-regulation of C-Met and Bcl2 by microRNA-206, activates apoptosis, and inhibits tumor cell proliferation, migration and colony formation. Oncotarget. 2015;6(28):25533-74.

48. Taulli R, Bersani F, Foglizzo V, Linari A, Vigna E, Ladanyi M, Tuschl T, Ponzetto C. The muscle-specific microRNA miR-206 blocks human rhabdomyosarcoma growth in xenotransplanted mice by promoting myogenic differentiation. J Clin Invest. 2009;1 19:2366-78.

49. Ewen ME, Lamb J. The activities of cyclin D1 that drive tumorigenesis. Trends Mol Med. 2004;10:158-62.

50. Zhou J, Tian Y, Li J, Lu B, Sun M, Zou Y, Kong R, Luo Y, Shi Y, Wang K, Ji G. miR-206 is down-regulated in breast cancer and inhibits cell proliferation through the up-regulation of cyclinD2. Biochem Biophys Res Commun. 2013;433(2):207-12

51. Huang B, Zhai W, Hu G, et al. MicroRNA-206 acts as a tumor suppressor in bladder cancer via targeting YRDC.Am. J TransI Res. 2016:8(11):4705-15.

52. Ren XL, He GY, Li XM, et al. MicroRNA-206 functions as a tumor suppressor in colorectal cancer by targeting FMNL2. J Cancer Res Clin Oncol. 2016;142(3):581-92

\section{Submit your next manuscript to BioMed Central and we will help you at every step:}

- We accept pre-submission inquiries

- Our selector tool helps you to find the most relevant journal

- We provide round the clock customer support

- Convenient online submission

- Thorough peer review

- Inclusion in PubMed and all major indexing services

- Maximum visibility for your research

Submit your manuscript at www.biomedcentral.com/submit 